\title{
Aggregation-Induced Emission Property of a Novel Pt(II) Metal Complex and Its Self-Sensitized Oxidation Reaction in Photo-Excitation State
}

\author{
WANG Shizhao, LI Weijun *, YU Yue, LIU Jin, ZHANG Cheng * \\ State Key Laboratory Breeding Base of Green Chemistry-Synthesis Technology, College of Chemical Engineering, International \\ Science \& Technology Cooperation Base of Energy Materials and Application, Zhejiang University of Technology, Hangzhou \\ 310014, P. R. China.
}

\begin{abstract}
AAbstract: The excited states of transition metal complexes with a wide range of photochemical and photophysical properties have attracted considerable attention recently. However, the luminescence property is affected by concentration quenching in practical applications. Aggregationinduced emission (AIE) is an effective strategy to solve this problem. In this work, a new imidazole-based $\mathrm{N}^{\wedge} \mathrm{C}^{\wedge} \mathrm{N} \mathrm{Pt}(\mathrm{II})$ metal complex, PtP2IM, with the AIE property was synthesized and characterized according to its single crystal structure. Under visible light, we found that the metal complex undergoes a photo-oxidation reaction with the generation of a new redemitting, imidazole/benzoylimino-based $\mathrm{N}^{\wedge} \mathrm{C}^{\wedge} \mathrm{N}^{\prime} \mathrm{Pt}(\mathrm{II})$ metal

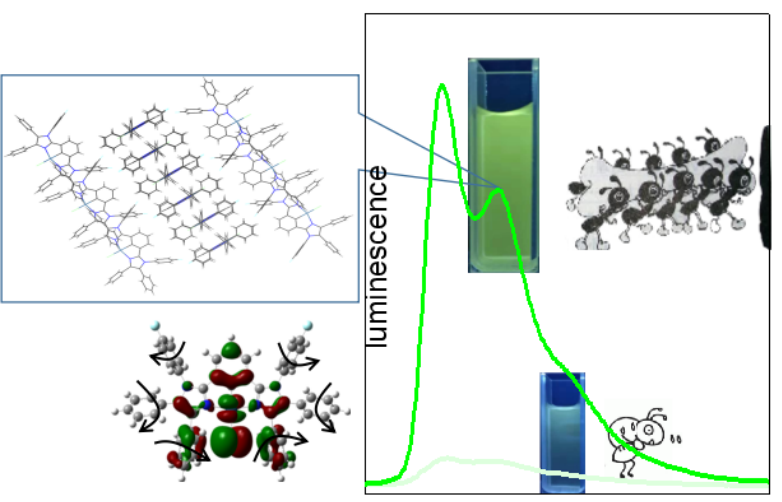
complex, PtPIMO, which was also confirmed by the crystal structure. Additional studies on the reaction process and conditions of this photo-oxidation reaction were conducted using different methods, such as NMR, UV-Vis spectroscopy, and so on. The experimental results showed that the change from PtP2IM to PtPIMO gradually occurred, and the new photochemical reaction was finally concluded as the $\mathrm{C}=\mathrm{C}$ double bond in either one of the two imidazole rings of the PtP2IM complex was attacked by oxygen to generate a new complex, PtPIMO, under photoirradiation in air. Electron paramagnetic resonance (EPR) measurements demonstrated the production of singlet oxygen, which is an excited state of oxygen with a high energy. Through the density functional theory (DFT) calculations, the electronic transition was determined to be a metal to ligand charge transfer (MLCT) in which more energy could transfer from the triplet excited state of PtP2IM to the ground-state oxygen to generate singlet oxygen $\left({ }^{1} \mathrm{O}_{2}\right)$ with a high intersystem crossing (ISC) efficiency due to the spin-orbit coupling of Pt heavy atoms. When large amounts of the singlet capture agent, triethylenediamine (TEDA) were added, the previously observed UV-Vis spectra change that corresponded to the photo oxidation reaction was not detected, which means that the photo-oxidation reaction observed in the case of PtP2IM was because of the oxidation by singlet oxygen. When oxygen was removed, excellent photostability and an obvious aggregation-induced emission (AIE) were observed for PtP2IM with the luminescent quantum efficiency of PtP2IM in solution and as a film at $\sim 3 \%$ and $\sim 20 \%$, respectively. Based on the packing structure in the crystal, we observed that there were no strong intermolecular interactions, such as $\pi-\pi$ or Pt-Pt interactions. Additionally, many intermolecular $\mathrm{CH}-\pi$ bonds between the two adjacent PtP2IM molecules were observed, which could effectively limit the rotation of the peripheral phenyl group linked to the imidazole ring. Thus, the AIE property of PtP2IM was attributed to the restricted intramolecular rotation (RIR) effect of the peripheral flexible phenyl group that was linked to the imidazole ring in the solid state in which the vibration of multiple peripheral benzene rings was effectively suppressed. This decreased the non-radiative transition rate and induced the high luminescent quantum efficiency. In the aggregation state, PtP2IM still
\end{abstract}

Received: February 19, 2019; Revised: March 18, 2019; Accepted: March 21, 2019; Published online: March 28, 2019.

${ }^{*}$ Corresponding authors. Emails: czhang@zjut.edu.cn (Z.C); liwj@zjut.edu.cn (L.W.). Tel: +86-571-88320929 (Z.C.).

The project was supported by the National Natural Science Foundation of China (51603185, 51673174), Zhejiang Provincial Natural Science Foundation of China (LQ19E030016, LY19E030006, LZ17E030001), China Postdoctoral Science Foundation (2018M632498), and the Zhejiang Provincial Postdoctoral fellowship, China (Z71101009).

国家自然科学基金(51603185, 51673174), 浙江省自然科学基金(LQ19E030016, LY19E030006, LZ17E030001), 国家博士后科学基金(2018M632498)及 浙江省博士后奖学金(Z71101009)资助项目

(C) Editorial office of Acta Physico-Chimica Sinica 
demonstrated the photo-oxidation reaction by singlet oxygen. Thus, we report a new $\mathrm{Pt}(\mathrm{II})$ metal complex, PtP2IM, with the AIE property that can undergo an uncommon photo-oxidation reaction in the photo-excitation state. This work aimed to elucidate the basic photochemical and photophysics of transition metal complexes with the AIE property.

Key Words: Pt(II) metal complex; Photo-oxidation reaction; Singlet oxygen; MLCT; AIE

\title{
具有聚集诱导发光特性的新型铂(II)金属配合物及其光激发的自敏化 氧化反应
}

\author{
王士昭, 李维军,, 俞越, 刘进, 张诚 \\ 浙江工业大学化学工程学院, 绿色化学合成技术国家重点实验室培育基地, 科技部能源材料及应用国际科技合作基地, \\ 杭州 310014
}

\begin{abstract}
摘要：现如今过渡金属配合物因其优良的物理、化学特性应用前景很好，但实际应用中浓度淬灭严重影响其性能。聚集 诱导发射(AIE)效应是一种常见的解决措施, 但基于金属配合物方面的报道还相对较少。本论文中报道了一个种具有AIE 效应的咪唑类金属Pt(II)配合物PtP2IM, 通过单晶解析了其结构。在可见光下, 该金属配合物可以发生光氧化反应生成一 种新的咪唑/苯酰胺基类配合物PtPIMO。通过单晶解析、核磁共振、紫外-可见光谱等测试手段对该反应进行了研究。电 子顺磁共振(EPR)测量结果显示PtP2IM的光氧化反应属于单态氧氧化反应。密度泛函理论(DFT)计算显示单线态氧是由 配合物MLCT的能量转移激发产生的。去除氧后, PtP2IM具有良好的光稳定性和明显的AIE特性。从晶体堆积中, 我们 发现PtP2IM的AIE特性可以归因于RIR效应即分子内旋转受限效应。聚集状态下, PtP2IM仍可以发生单线态氧的光氧化 反应。综上所述, 我们报道了一种具有AIE特性的新型铂(II)金属络合物PtP2IM, 光激发下可以发生自敏化反应。本工作 旨在研究具有AIE性质的过渡金属配合物的基本光化学和光物理性质。
\end{abstract}

关键词: 金属铂(II)配合物; 光氧化反应; 单线态氧; 金属-配体电荷跃迁; 聚集诱导发光 中图分类号: 0644

\section{Introduction}

In recent years, transition-metal complexes with populated excited states upon excitation possess a rich range of photochemical and photophysical properties ${ }^{1-12}$, which have attracted much attention regarding their capability to exhibit intense phosphorescence in applications such as organic light emitting diodes (OLEDs) ${ }^{2-4}$, photocatalysis ${ }^{5-7}$, sensors ${ }^{8-10}$ and a new application in photodynamic therapy (PDT) ${ }^{11,12}$. Among them, platinum(II) complexes represent an important class of compounds, owing to the heavy atom effect of platinum, the efficient generation of the intersystem crossing (ISC) efficiency makes the platinum(II) complexes a better phosphorescence emission performance.

Singlet oxygen $\left({ }^{1} \mathrm{O}_{2}\right)$, one species of the reactive oxygen species (ROS) ${ }^{13}$, is the excited state of $\mathrm{O}_{2}$ with high energy, which turn to be the new star in photodynamic therapy (PDT) in cancer treatment ${ }^{14}$ and bacterial phagocytosis ${ }^{15}$. Singlet oxygen is usually generated through the energy transfer from the triplet excited state molecules photosensitizer (PS) to the ground state of triplet oxygen $\left({ }^{3} \mathrm{O}_{2}\right)$.

Hence, the efficient generation of ${ }^{1} \mathrm{O}_{2}$ is habitually related to the ISC efficiency of the sensitizer and concentration quenching of the excited state ${ }^{16-20}$. Nowadays, interposition of heavy atoms into molecular structures is one of the most widely used approaches to improve the ISC efficiency due to the enhanced spin-orbit coupling in the excited state, which can make more energy transfer from the $T_{1}$ state of the photosensitizer to the ground-state oxygen to generate the ${ }^{1} \mathrm{O}_{2}{ }^{19}$. As such, to solve the concentration quenching of the excited state is another way to affect the efficiency of ${ }^{1} \mathrm{O}_{2}$ generation. Since Tang team found the aggregation-induced emission (AIE), AIE materials have been widely applied in the preparation of efficient light-emitting devices and chemical biological sensors, due to their enhanced fluorescence and efficient photosensitizing characteristics ${ }^{21-23}$. Thus AIE might be an effective strategy to solve the concentration quenching of the excited state and enhance the efficiency of ${ }^{1} \mathrm{O}_{2}$ generation. It is obvious that the transitionmetal complexes with AIE property might simultaneously possess a high ISC efficiency and the non-concentration quenching, which is favourable to the generation of ${ }^{1} \mathrm{O}_{2}$.

Herein, a new imidazole-based $\mathrm{N}^{\wedge} \mathrm{C}^{\wedge} \mathrm{N} \mathrm{Pt}(\mathrm{II})$ metal complex PtP2IM was synthesized, expected to obtain a material with an AIE performance. It was founded to undergo a photo-oxidation reaction with the generation of a new asymmetry, red-emitted, imidazole/benzoylimino-based $\mathrm{N}^{\wedge} \mathrm{C}^{\wedge} \mathrm{N} \mathrm{Pt}(\mathrm{II})$ metal complex under the visible light. More studies of the photo-oxidation reaction demonstrated that the photo-oxidation reaction observed in the case of PtP2IM belonged to the oxidation of singlet oxygen, which was generated from the photo sensitization of PtP2IM itself. When oxygen $\left({ }^{3} \mathrm{O}_{2}\right)$ was removed, 
an obvious AIE and an excellent photostability were observed for PtP2IM. The AIE property of PtP2IM was attributed to the RIR (restricted intramolecular rotation) effect of the peripheral flexible phenyl group linked to imidazole ring in solid state. In aggregation state, PtP2IM still demonstrated the photo-oxidation reaction by singlet oxygen.

\section{Experimental and computational section}

All of the reagents and solvents used for the syntheses purchased from Energy were used without further purification with a purity of above $98 \%$. All of the reactions were performed under a dry-nitrogen atmosphere. ${ }^{1} \mathrm{H}(500 \mathrm{MHz}) \mathrm{NMR}$ spectra of the synthesized compounds were recorded on Bruker AVANCE III instrument (Bruker, Switzerland). Mass spectra (MALDI-TOF-MS) analysis was recorded using an AXIMACFRTM plus instrument (Kratos Analytical, England). The single crystal structure was carried out with an Agilent Geminie instrument. Photophysical properties were investigated by a Shimadzu UV-1800 spectrophotometer (Shimadzu, Japan) and a Perkin-Elmer LS-55 luminescence spectrophotometer (America). The fluorescence quantum yield was determined by a calibrated integrating sphere. The photo irradiation was carried in a ZF-20D ultraviolet analyzer (YUHUA, China) with a UV light $(365 \mathrm{~nm}, 25 \mathrm{~mW})$. All measurements were carried out at room temperature under ambient conditions. Density functional theory (DFT) was calculated using Gauss $09^{24}$.

\section{Results and discussion}

\subsection{Synthesis}

See the synthesis part in the Supporting Information for experimental details, as shown in Fig. S1 (Supporting Information).

\subsection{Crystal structure}

Through the solution growth method, single crystals of PtP2IM suitable for XRD analysis were obtained and their crystal structure was shown in Fig. 1a. An interesting thing was that some red crystalline solids were also observed as suspensions in the solution. After a careful analysis, we found that the suspended red crystalline solids was not attributed to a

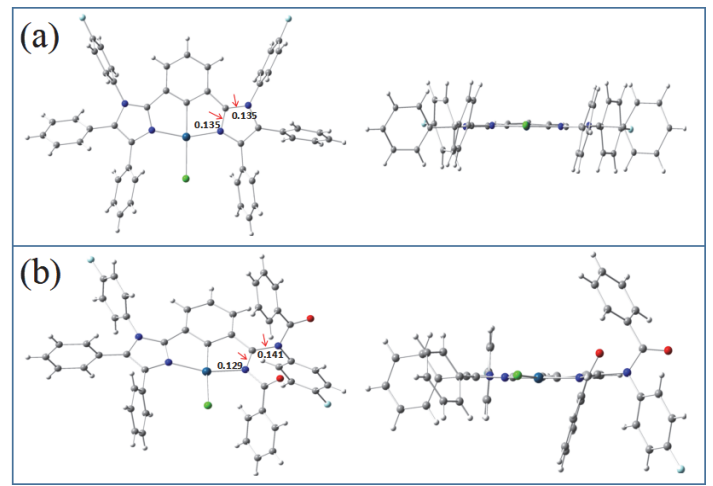

Fig. 1 The newly-obtained single-crystal structure of (a) PtP2IM (CCDC 1891478) and (b) PtPIMO (CCDC 1891487). second crystal with strong Pt-Pt interaction but a new complex molecule different from PtP2IM, which indicated that PtP2IM underwent a chemical reaction to generate a new red compound in the given conditions. After accumulating large amounts of red solid, the single crystals suitable for XRD analysis were also obtained and the new crystal structure was shown in Fig. 1 b.

In Fig. 1a, the crystal structure of PtP2IM clearly showed the typical $\mathrm{N}^{\wedge} \mathrm{C}^{\wedge} \mathrm{N} \mathrm{Pt}(\mathrm{II})$ metal complex structure and the imidazole structure as a five-member ring in the ligand part. While in Fig. $1 b$, the new crystal structure showed a new molecule PtPIMO with a benzoylimino-benzamide structure verified by measured $\mathrm{C}-\mathrm{N}$ and $\mathrm{C}=\mathrm{N}$ bond lengths of 0.141 and $0.129 \mathrm{~nm}$, respectively. From the contrast of crystal structures in Figs. 1a and $1 \mathrm{~b}$, it could be concluded that an oxidation reaction from PtP2IM to PtPIMO occurred, in which one of the two imidazole rings in PtP2IM was opened to generate a benzoyliminobenzamide structure. NMR spectra further confirmed the molecular structure of PtPIMO as shown in Fig. S2 (Supporting Information).

\subsection{Photo-oxidation reaction}

In order to further investigate this oxidation reaction from PtP2IM to PtPIMO, the in-situ UV-Vis absorption spectra were measured as shown in Fig. 2. PtP2IM displayed a strong absorption band between 365 and $420 \mathrm{~nm}$ with an absorption maximum peak at $\sim 400 \mathrm{~nm}$, which was much redshifted in comparison to that of pure ligand P2IM and might be attributed to the low-energy MLCT transition in PtP2IM. When the UV irradiation $(365 \mathrm{~nm}, 25 \mathrm{~mW})$ was applied on the PtP2IM solution, the MLCT absorption band around $400 \mathrm{~nm}$ began to descend in intensity and at the same time a new peak appeared around $450 \mathrm{~nm}$, which just corresponded to that of PtPIMO with an absorption maximum peak at $\sim 450 \mathrm{~nm}$. As the UV irradiation time was prolonged, the peaks at 400 and $450 \mathrm{~nm}$ corresponding to PtP2IM and PtPIMO respectively kept to further descend and increase gradually. Thus it could be seen that PtP2IM underwent a chemical reaction to generate the PtPIMO under the UV irradiation condition.

In order to further study this chemical reaction from PtP2IM to PtPIMO, we then took more steps to explore the condition that

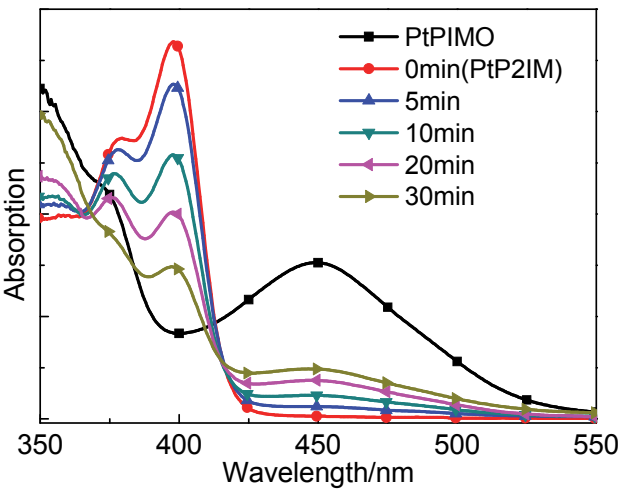

Fig. 2 The in-situ UV-Vis absorption spectra of PtP2IM under the UV irradiation. 
could initiate the reaction, as show in Fig. 3. Firstly, under dark condition without UV irradiation (Fig. 3a), PtP2IM dissolved in dichloromethane could keep stable in UV-Vis spectra after three days, with no new peaks corresponding to PtPIMO appeared. It indicated that the reaction from PtP2IM to PtPIMO belonged to a photo chemical reaction that occurred at the excited state and would not happen under the condition lack of light. Secondly, through a strict oxygen removal operation to achieve a $\mathrm{N}_{2}$ atmosphere, the PtP2IM solution still kept stable after $30 \mathrm{~min}$ irradiation (Fig. 3b). It indicated that oxygen in air was another necessary condition for the observed photo-chemical reaction from PtP2IM to PtPIMO.

Herein, a photochemical reaction could be finally concluded as shown in Fig. 4, in which the $\mathrm{C}=\mathrm{C}$ double bond in either one of the two imidazole ring of the PtP2IM complex was attacked by oxygen to generate the benzoylimino and benzamide group and produce a new complex PtPIMO under the photo irradiation condition. Interesting was that the further oxidation reaction of the other imidazole ring in PtPIMO was tentatively not observed obviously in current experiments.

As for the photo oxidation of imidazole, singlet oxygen was commonly regarded as the oxidation agent ${ }^{25,26}$. In order to further confirm the mechanism of this observed photo oxidation reaction in PtP2IM. The 2,2,6,6-tetramethyl piperidine (TEMP) was selected as the capture agent to character the signal of singlet oxygen by electron paramagnetic resonance (EPR). As shown in Fig. 5, the signals of nitroxide radicals TEMP $^{-}{ }^{1} \mathrm{O}_{2}$ adduct (TEMPO) corresponding to that of singlet oxygen was observed, indicated that the singlet oxygen was generated in PtP2IM

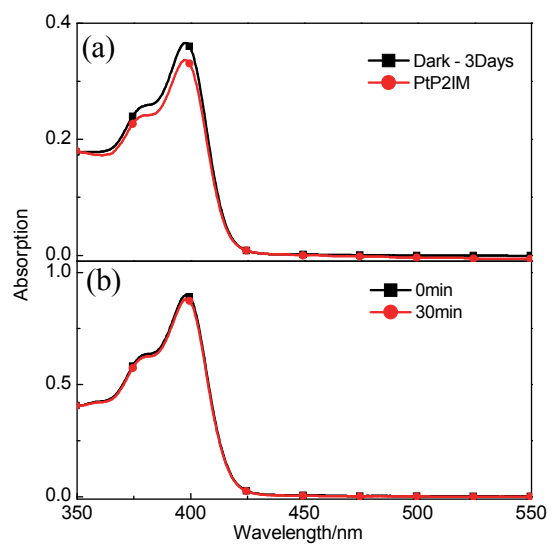

Fig. 3 The UV-Vis absorption spectra of PtP2IM under (a) dark condition in air for three days, (b) anaerobic environment with the reagent fully deoxygenated.

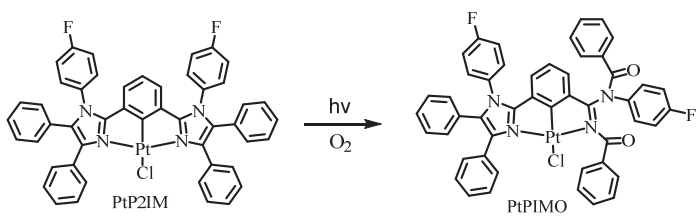

Fig. 4 The photo-oxidation reaction equation from PtP2IM to PtPIMO. solution. When large amounts of triethylenediamine (TEDA) ${ }^{27}$ were added into PtP2IM solution as shown in Fig. S3 (Supporting Information), the previously observed UV-Vis spectra change corresponding to the occurrence of photo oxidation reaction was not detected, which indicated the stop of photo oxidation reaction due to the quickly capture and quench of singlet oxygen in the presence of large amounts of TEDA. It also further demonstrated a fact that singlet oxygen played a key role in the observed photo oxidation reaction of PtP2IM. Thus it could be concluded that PtP2IM could produce ${ }^{1} \mathrm{O}_{2}$ under light irradiation and further undergo the self-sensitized photo oxidation reaction to generate the PtPIMO complex via singlet oxygen.

\subsection{DFT calculations}

The electronic orbital of the metal complex PtP2IM was studied with the time-dependent density functional theory (TDDFT) methods as shown in Fig. 6. The frontier molecular orbitals was distributed on the $\mathrm{Pt}(\mathrm{II})$ center and the ligands. The electron cloud of LUMO is mainly located on the main ligand P2IM, while the electron cloud of HOMO and HOMO-1 was mainly distributed on the $\mathrm{Pt}(\mathrm{II})$ and chlorine atoms. Thus the $S_{0}-$ $S_{1}, S_{0}-S_{2}$ transition of complex consisted by HOMO $\rightarrow$ LUMO and HOMO- $1 \rightarrow$ LUMO transition could be recognized as a MLCT transition, which could ensure that more energy could transfer from the $T_{1}$ state of the photosensitizer to the groundstate oxygen to generate the ${ }^{1} \mathrm{O}_{2}$ with a high ISC efficiency due to the spin-orbit coupling of heavy atoms Pt.

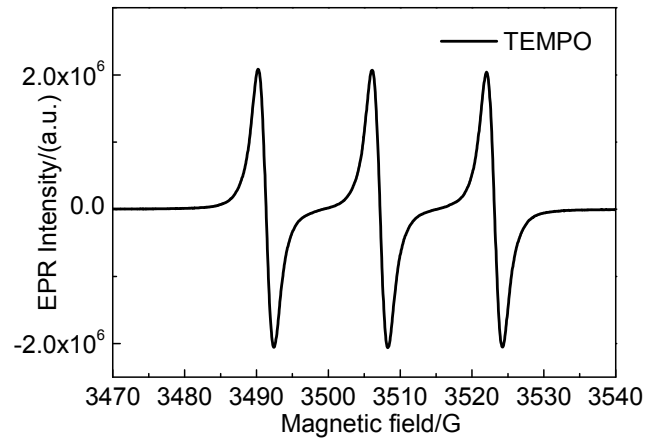

Fig. 5 EPR spectrum of the TEMP- ${ }^{1} \mathrm{O}_{2}$ radical during irradiation of $\mathrm{Pt}(\mathrm{P} 2 \mathrm{IM})$ suspended in $\mathrm{CH}_{2} \mathrm{Cl}_{2}$ and TEMP.

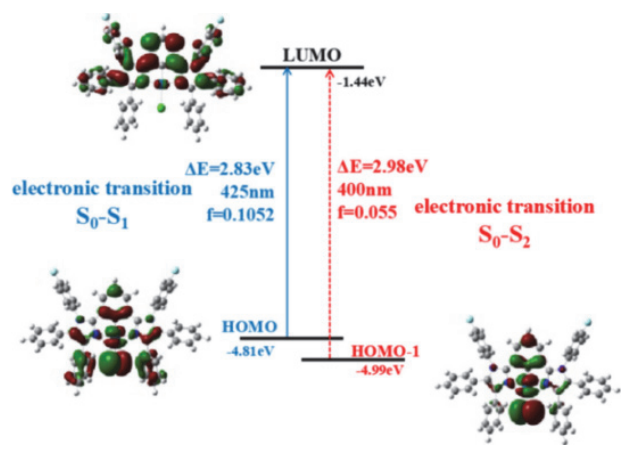

Fig. 6 Frontier molecular orbitals for complex PtP2IM calculated by TD-DFT at the B3LYP/6-31G $(d, p)+/$ LanL2DZ level using the geometry of the $S_{0}$ state. 


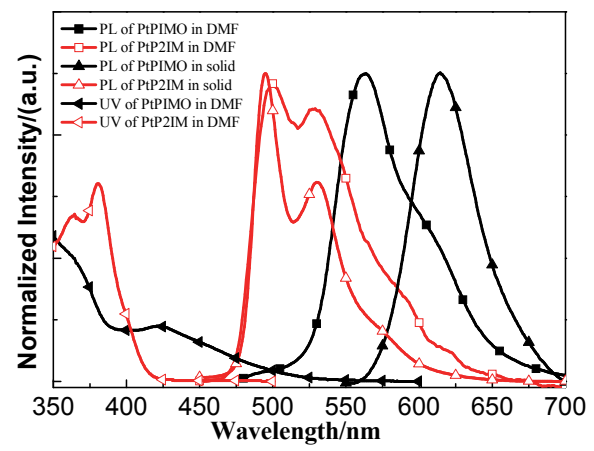

Fig. 7 The UV-Vis and PL spectra of PtP2IM and PtPIMO in DMF and solid state.

\subsection{Photoluminescence properties}

It was obvious that PtP2IM could display a stable phosphorescent emission without the occurrence of photooxidation reaction if oxygen was removed. With the lack of oxygen, PtP2IM showed a green emission with $\lambda_{\max }$ at $500 \mathrm{~nm}$ in solution state as shown in Fig. 7. In solid state, PtP2IM also displayed a green emission with $\lambda_{\max }$ at $495 \mathrm{~nm}$, which was a little blueshift in comparison to that in solution. Compared to PtP2IM, the photo-oxidation product PtPIMO had an orange-red emission with $\lambda_{\max }$ at about $560 \mathrm{~nm}$ in solution state, which could keep stable in the same condition. The redshifted PL spectra of PtPIMO could be attributed to a new lower-energy MLCT transition between the metal to the newly formed benzoyliminobenzamide part in ligand structure, which could be found in the UV-Vis spectra of PtPIMO at around $425 \mathrm{~nm}$. In solid state, PtPIMO displayed a red emission with $\lambda_{\max }$ at about $610 \mathrm{~nm}$. By using an integrating sphere photometer, the luminescent quantum efficiency of PtP2IM in solution and film were measured to be $\sim 3 \%$ and $\sim 20 \%$, respectively. The higher quantum luminescence efficiency of PtP2IM in film than solution indicated the possible characteristics of aggregationinduced emission (AIE) effect ${ }^{28,29}$. We also measured the luminescent quantum efficiency of PtPIMO in solution and film to be only $\sim 3( \pm 2) \%$ respectively. The relatively low luminescence quantum efficiencies of PtP2IM and PtPIMO might be ascribed to the large non-radiative transition rate derived from the vibration of multiple peripheral benzene rings linked to the imidazole rings.

In order to further investigate the AIE properties of PtP2IM, their PL spectra in water/ $N, N$-dimethylformamide (DMF) solvents with different water proportions $(V / V)$ were measured. With the addition of more proportions of water $(V / V)$ into the DMF solution of PtP2IM, an obvious AIE phenomenon of PtP2IM was observed with the PL intensity increasing and reaching the maximum at the water proportion of $90 \%$, as shown in Fig. 8a. No obvious shifts were observed in PL spectra for PtP2IM in water/DMF solvents from lower water proportions to higher ones. From the packing structure in crystal as shown in Fig. S4 (Supporting Information), we could see that there were none strong intermolecular interactions like $\pi-\pi$ or $\mathrm{Pt}-\mathrm{Pt}$
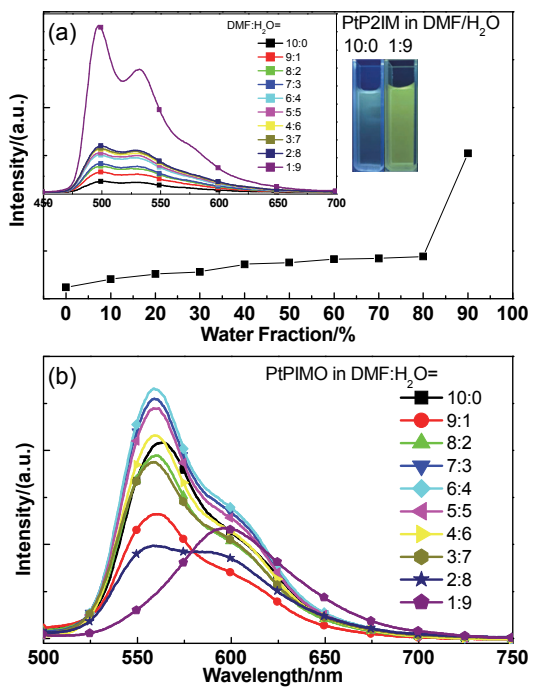

Fig. 8 Plots of maximum PL peak intensity of PtP2IM (a) and PtPIMO (b) versus water fraction in the DMF/water mixtures (solution concentration: $7 \times 10^{-6} \mathrm{~mol} \cdot \mathrm{L}^{-1}$, excitation wavelength: $365 \mathrm{~nm}$ to PtP2IM and $400 \mathrm{~nm}$ to PtPIMO).

interaction, and many intermolecular $\mathrm{CH}-\pi$ bonds between the two adjacent PtP2IM molecules were observed, which could effectively limit the rotation of the peripheral phenyl group linked to the imidazole ring. Thus, the RIR (restricted intramolecular rotation) effect was thought to be the main reason for the observed AIE property in PtP2IM, in which the vibration of multiple peripheral benzene rings linked to the imidazole structure were effectively suppressed in the solid state which decreased the non-radiative transition rate and induced the high luminescent quantum efficiency.

Under the same experimental condition, with the addition of water into the DMF solution of PtPIMO, no obvious AIE phenomenon was observed in Fig. 8b. As the water content increased and reached the water proportion of $80 \%$, the original PL intensity at $560 \mathrm{~nm}$ kept going down until disappearance, and resulted in the shoulder peak at $\sim 600 \mathrm{~nm}$ at last which was consistent with the PL spectra of PtPIMO in solid state. Obviously, the photo-oxidation product PtPIMO showed none AIE properties.

Considering the AIE effect in PtP2IM still might contribute to the yield of ${ }^{1} \mathrm{O}_{2}$, a controlled experiment of self-sensitization was carried as shown in Fig. S5 (Supporting Information). After 5 min irradiation in DCM, there was a decrease in the absorption of PtP2IM, which means the generation of ${ }^{1} \mathrm{O}_{2}$. However, contrasted with the same concentration of PtP2IM in DMF/ $\mathrm{H}_{2} \mathrm{O}$ volume ratio $=1: 9$, the reduction of the absorbance was remarkable under the same light irradiation. Obviously PtP2IM demonstrated a non-concentration quenching in solid state based on the AIE effect.

\section{Conclusions}

In summary, we have finally got a new $\mathrm{Pt}(\mathrm{II})$ metal complex PtP2IM with AIE property which can undergo a photo-oxidation 
reaction at photo-excitation state. PtP2IM undergoes a photooxidation reaction to generate a new metal complex PtPIMO with a benzoylimino-benzamide structure. Light irradiation and oxygen (air) are confirmed to be the two necessary conditions for the observed photo-chemical reaction from PtP2IM to PtPIMO. The photo-oxidation reaction observed in the case of PtP2IM belonged to the oxidation by singlet oxygen, which was also confirmed to be generated from the photo sensitization of PtP2IM itself. And a non-concentration quenching could be observed for PtP2IM in the solid state, due to the RIR effect which is favorable to the generation of ${ }^{1} \mathrm{O}_{2}$. It provides us with a promising way to design an efficient photosensitizer by using an AIE metal complex.

Supporting Information: available free of charge via the internet at http://www.whxb.pku.edu.cn.

\section{References}

(1) Li, K.; Tong, G. S. M.; Wan, Q. Y.; Cheng, G.; Tog, W. Y.; Ang, W H.; Kwong, W. L.; Che, C. M. Chem. Sci. 2016, 7, 1653. doi: $10.1039 / \mathrm{c} 5 \mathrm{sc} 03766 \mathrm{~b}$

(2) Zhang, S. T.; Yao, L.; Peng, Q. M.; Li, W. J.; Pan, Y. Y.; Xiao, R.; Gao, Y.; Gu, C.; Wang, Z. M.; Lu, P.; et al. Adv. Funct. Mater. 2015, 25, 1755. doi: 10.1002/adfm.201404260

(3) Wei, C. D.; Ge, G. P.; Li, C. Y.; Lei, K. W.; Liang, H. Z.; Yu, G.; Liu, Z. W. Acta Phys. -Chim. Sin. 2015, 31, 17. [韦传东, 葛国平, 李春艳, 雷克微, 梁洪泽, 禹钢, 刘志伟. 物理化学学报, 2015, 31, 17.] doi: 10.3866/PKU.WHXB201411212

(4) Wang, J.; Zhang, F. J.; Xu, Z.; Wang, Y. S. Acta Phys. -Chim. Sin. 2012, 28,949. [王健, 张福俊, 徐征, 王永生. 物理化学学报, 2012, 28, 949.] doi: 10.3866/PKU.WHXB201201163

(5) Zhang, J.; Du, P. W.; Schneider, J.; Jarosz, P.; Eisenberg, R. J. Am. Chem. Soc. 2007, 129, 7726. doi: 10.1021/ja071789h

(6) Zhong, J. J.; Yang, C.; Chang, X. Y.; Zou, C.; Lu, W.; Che, C. M. Chem. Commun. 2017, 53, 8948. doi: 10.1039/c7cc03823b

(7) Xiao, J. D.; Shang, Q. C.; Xiong, Y. J.; Zhang, Q.; Luo, Y.; Yu, S. H.; Jiang, H. L. Angew. Chem. Int. Ed. 2016, 55, 1. doi: 10.1002/anie. 201603990

(8) Grove, L. J.; Rennekamp, J. M.; Jude, H.; Connick, W. B. J. Am. Chem. Soc. 2004, 126, 1594. doi: 10.1021/ja037783j

(9) Zhang, M. M.; Saha, M. L.; Wang, M.; Zhou, Z. X.; Song, B.; Lu, C. J.; Yan, X. Z.; Li, X. P.; Huang, F. H.; Yin, S. C.; et al. J. Am. Chem Soc. 2017, 139, 5067. doi: 10.1021/jacs.6b12536

(10) Saha, M. L.; Yan, X. Z.; Stang, P. J. Acc. Chem. Res. 2006, 49, 2527. doi: 10.1021/acs.accounts.6b00416

(11) Garcia-Chocano, V. M.; Sanchez-Dehesa, J. Appl. Catal. B 2006, 69, 1. doi: 10.1016/j.apacoust.2012.06.008

(12) Zhou, J.; Zhang, Y. Z.; Yu, G. C.; Crawley, M. R.; Fulong, C. R. P.; Friedman, A. E.; Sengupta, S.; Sun, J. F.; Li, Q.; Huang, F. H.; et al. J. Am. Chem. Soc. 2018, 140, 7730. doi: 10.1021/jacs.8b04929
(13) Nosaka, Y; Nosaka, A. Y. Chem. Rev. 2017, 117, 11302. doi: 10.1021/acs.chemrev.7b00161

(14) Ge, J. C.; Lan, M. H.; Zhou, B. J.; Liu, W. M.; Guo, L.; Wang, H.; Jia, Q. Y.; Niu, G. L.; Huang, X.; Zhou, H. Y. Nat. Commun. 2014, 5, 4596. doi: $10.1038 /$ ncomms5596

(15) von Kockritz-Blickwede, M.; Goldmann, O.; Thulin, P.; Heinemann, K.; Norrby-Teglund, A.; Rohde, M.; Medina, E. Blood 2008, 111, 6 doi: 10.1182/blood-2007-07-104018

(16) Yogo, T.; Urano, Y.; Ishitsuka, Y.; Maniwa, F.; Nagano, T. J. Am. Chem. Soc. 2005, 127, 12162. doi: 10.1021/ja0528533

(17) Zhao, J. Z.; Wu, W. H.; Sun, J. F.; Guo, S. Chem. Soc. Rev. 2013, 42, 5323. doi: $10.1039 / \mathrm{c} 3 \operatorname{cs} 35531 \mathrm{~d}$

(18) Adarsh, N.; Avirah, R. R.; Ramaiah, D. Org. Lett. 2010, 12, 5720 doi: $10.1021 / \mathrm{ol} 102562 \mathrm{k}$

(19) Zhou, C. J.; Zhang, S. T.; Gao, Y.; Liu, H. C.; Shan, T.; Liang, X. M.; Yang, B.; Ma, Y. G. Adv. Funct. Mater. 2018, 1802407. doi: $10.1002 / \mathrm{adfm} .201802407$

(20) Yin, L.; Liang, C.; Chen, K. X.; Zhao, C. X.; Yao, J.; Li, H. R. Acta Phys. -Chim. Sin. 2017, 33, 1390. [尹璐, 梁程, 陈可先, 赵琛烜, 姚加, 李浩然. 物理化学学报, 2017, 33, 1390.] doi: 10.3866/PKU.WHXB201704111

(21) Shi, H. B.; Liu, J. Z.; Geng, J. L.; Tang, B. Z.; Liu, B. J. Am. Chem. Soc. 2012, 134, 9569. doi: 10.1021/ja302369e

(22) Chen, S. J.; Hong, Y. N.; Liu, Y.; Liu, J. Z.; Leung, C. W. T.; Li, M.; Kwok, R. T. K.; Zhao, E. G.; Lam, J. W. Y.; Yu, Y. J. Am. Chem. Soc. 2013, 135, 4926. doi: 10.1021/ja400337p

(23) Ding, D.; Goh, C. C.; Feng, G. X.; Zhao, Z. J.; Liu, J.; Liu, R. R.; Tomczak, N.; Geng, J. L.; Tang, B. Z.; Ng, L.G. Adv. Mater. 2013, 25, 6083. doi: 10.1002/adma.201301938

(24) Atkins, A. J.; Talotta, F.; Freitag, L.; Boggio-Pasqua, M.; Gonzalez, L. J. Chem. Theory Comput. 2017, 13, 4123. doi: 10.1021/acs.jctc.7b00379

(25) White, E. H.; Harding, M. J. C. Photochem. Photobiol. 1965, 4, 1129. doi: 10.1111/j.1751-1097.1965.tb09302.x

(26) Yu, Y.; Zhao, R. Y.; Zhou, C. J.; Sun, X. Y.; Wang, S. Z.; Gao, Y.; Li, W. J.; Lu, P.; Yang, B.; Zhang, C. Chem. Commun. 2019, 55, 977. doi: $10.1039 / \mathrm{C} 8 \mathrm{CC} 08558 \mathrm{G}$

(27) Baciocchi, E.; Del Giacco, T.; Elisei, F.; Gerini, M. F.; Guerra, M.; Lapi, A.; Liberali, P. J. Am. Chem. Soc. 2003, 125, 16444. doi: 10.1021/ja037591

(28) Liu, J.; Li, W. J.; Liu, M. J.; Dong, Y. J.; Dai, Y. Y.; Song, Q. B.; Wang, J. L.; Zhang, C. Phys. Chem. Chem. Phys. 2018, 20, 28279. doi: $10.1039 / \mathrm{C} 8 \mathrm{CP} 05581 \mathrm{E}$

(29) Li, W. J.; Wang, S. Z.; Zhang, Y. J.; Gao, Y.; Dong, Y. J.; Zhang, X.; Song, Q. B.; Yang, B.; Ma, Y. G.; Zhang, C. J. Mater. Chem. C 2017, 5, 8097. doi: 10.1039/C7TC02474F 